\title{
Por trás do discurso socialmente responsável da siderurgia mineira
}

\author{
Marcelo Aureliano Monteiro de Andrade ${ }^{\mathrm{a}, *}$, Marlusa Gosling ${ }^{\mathrm{b}}$, Wescley Silva Xavier \\ a,*abbigbh@yahoo.com.br, UFMG, Brasil \\ bmarlusa@ufmg.br, UFMG, Brasil \\ 'wescleysxavier@yahoo.com.br, UFMG, Brasil
}

\begin{abstract}
Resumo
A Responsabilidade Social Corporativa (RSC) é um tema relevante e recentemente tem estimulado vários debates científicos, enfocando as vantagens que apresenta aos negócios em geral e à sociedade. Num esforço para explorar processos organizacionais de RSC, o principal objetivo do presente estudo é analisar o balanço social de empresas brasileiras. 0 framework da análise embasa-se no conteúdo publicado do instrumento (balanço social) ao longo de de 2 anos. As unidades de análise são duas grandes empresas do setor siderúrgico de Minas Gerais. Usamos análise de conteúdo e de fotografias (BAUER, 2004; BARDIN, 2004) para atingir os objetivos da pesquisa. Para dar suporte à análise de conteúdo, usamos a pirâmide de Carroll (1991) como abordagem teórica. Os resultados mostram que apesar do discurso das empresas focar-se principalmente em razões éticas para investir em RSC, a motivação real é reforço da marca e do posicionamento corporativo.
\end{abstract}

Palavras-chave

Responsabilidade social. Balanço social. Sustentabilidade. Global Reporting Initiative - GRI.

\section{A Responsabilidade Social Corporativa (RSC) e a pirâmide da responsabilidade social de Carroll (1991)}

0 que se entende hoje por Responsabilidade Social Corporativa, de acordo com Tenório (2006), é uma construção que vem desde o início do período capitalista, no século XVIIl, quando se imaginava, a partir da obra de autores liberais como Adam Smith, que a função das empresas era apenas a geração de ganhos para seus donos ou acionistas. Acreditava-se que assim aconteceria a livre concorrência entre organizações e que esse era o mecanismo perfeito para a regulamentação do mercado e a geração de riqueza que provesse a sociedade. A intervenção do Estado sobre a economia deveria ser mínima, uma vez que as organizações seriam capazes de gerar empregos e, consequentemente, bem-estar a todos (MONTORO FlLHO et al., 2001).

Essa concepção prevaleceu no mundo ocidental até o início do século XX. Mais precisamente até a queda da Bolsa de Nova York, em 1929, quando se percebeu que a economia livre do controle estatal era insustentável e gerava grandes desequilíbrios sociais. Notou-se que as organizações privadas com sua lógica da maximização constante de ganhos não davam garantias de bem-estar e segurança aos trabalhadores, assim como não investiam em áreas importantes da sociedade, deixando desprovidos setores essenciais para a sustentação social. É nessa época que surge, a partir da obra de John Keynes, a idéia do estado intervencionista, que regulamenta e financia a economia e as relações trabalhistas (TENÓRIO, 2006). 0 modelo de Keynes, apesar de ter gerado um alto custo em termos de impostos, permitiu após a Segunda Grande Guerra, especialmente nos países desenvolvidos - onde a proposta da teoria de Keynes foi, de fato, posta em prática -, que as organizações pudessem trabalhar em um ambiente de menos incerteza, investindo maciçamente na sua produção e desenvolvimento tecnológico, o que lhes trouxe enormes ganhos. De fato, Singer (2002) sustenta que: 
Apesar da volta do liberalismo, o panorama teórico da economia nunca mais será o mesmo; tampouco o da política. A razão disso é que a teoria de Keynes foi aplicada no mundo inteiro, dos anos 30 aos 70 do século passado, e deu certo. Durante mais de 30 anos o pleno emprego foi geral, e o comando do Estado sobre a economia capitalista garantiu altas taxas de crescimento do produto, da produtividade, de emprego e dos salários (SINGER, 2002, p. 14).

Esse modelo funcionou bem durante quatro décadas, mas nos anos 1980, principalmente com o sucesso da política econômica liberal na Inglaterra, houve uma volta aos moldes do início do século $\mathrm{XX}$, que passaram a denominar "neoliberalismo" (SINGER, 2002). Buscou-se então o enxugamento do Estado e, consequentemente, a sublimação de algumas conquistas que a sociedade tivera nas décadas anteriores. Em muitos lugares essa nova política levou forte desemprego e o reaparecimento de diversas mazelas sociais. Isso, aliado aos ganhos que as sociedades tiveram com o Estado interventor das décadas anteriores, o desenvolvimento das tecnologias da informação, o aumento do nível de escolaridade em geral e o surgimento de grandes problemas ambientais fez com que surgisse uma cobrança: a de que as lacunas abertas pela nova economia fossem fechadas.

Tenório (2006), a partir das proposições de Toffler (1995), afirma que a sociedade industrial - típica do período liberal - tinha como valor central o sucesso econômico, enquanto a sociedade pós-industrial - característica do modelo keynesiano - passou a estimar também o:

[...] aumento da qualidade de vida; a valorização do ser humano; o respeito ao meio ambiente; a organização empresarial de múltiplos objetivos; e a valorização das ações sociais, tanto das empresas quanto dos indivíduos (TENÓRIO, 2006, p. 20).

As sociedades então, quando o Estado deixou de ser o provedor, passam a demandar das organizações não somente a boa qualidade dos produtos, da distribuição e dos preços, mas também um compromisso empresarial com a ética, o desenvolvimento social e o respeito à natureza, ambiente ideal para que o debate teórico e a prática da Responsabilidade Social Corporativa (RSC, daqui por diante) se intensificassem.

Atualmente, a RSC é entendida como uma política que visa um relacionamentojusto da empresa com todos os stakeholders, abrangendo também o respeito aos limites ambientais na produção. Vale salientar que o termo RSC ainda é bastante debatido na academia e ainda não há consenso sobre seu significado (CHAHAL; SHARMA, 2006; CARROLL, 1999), porém, para a maior parte dos autores que trabalham o tema, somente a partir do preenchimento dos requisitos citados pode-se buscar o lucro. Ou seja, a organização nesta óptica é vista como parceira da sociedade em seu desenvolvimento e na geração da qualidade de vida das pessoas (ASHLEY, 2002).

Um dos modelos mais alicerçados sobre a RSC no meio acadêmico e que serviu de parâmetro para as análises que serão apresentadas a seguir, é a Pirâmide da Responsabilidade Social, de Carroll (1991). Para esse framework, fazem parte do dia-a-dia das empresas muitos stakeholders, como: empregados, clientes, acionistas, comunidades de entorno, sindicatos, poder público, imprensa. Carroll (1991) salienta que, independentemente do nível de importância de cada grupo para cada empresa, todos os stakeholders impactam e são impactados pelas ações da organização e por isso precisam ser considerados em um projeto de RSC. Para o autor, cada um desses grupos apresentará demandas diferentes, e em diferentes quantidades, para uma empresa - doações, boas condições de trabalho, retorno financeiro, pagamento dos impostos, transparência nas informações etc. -, mas todos têm importância para a sobrevivência institucional e merecem, dentro de uma política de responsabilidade social, serem tratados com justiça e muitas vezes benevolência.

Desta forma, em seu modelo, Carroll (1991) dividiu essas demandas dos diferentes públicos a partir de quatro dimensões: a econômica, que se refere ao retorno financeiro da organização; a legal, que remete ao cumprimento pela empresa a todos as normas legais vigentes; a ética, que diz respeito ao tratamento justo e equitativo de todos os públicos da organização; e a filantrópica, que trata das ações de filantropia que a empresa realiza entre as comunidades com as quais se relaciona. 0 autor salienta ainda que essas dimensões são dinâmicas, que elas se complementam e têm importância no contexto da RSC - mesmo que muitas vezes existam conflitos entre elas, especialmente entre a dimensão econômica e as demais.

Carroll (1991), apesar desse dinamismo, dispõe as dimensões em uma pirâmide pelo nível de importância que cada uma tem na sobrevivência da empresa (Figura 1). As dimensões econômica e legal, respectivamente, ficam na base, pois o seguimento dos seus preceitos é essencial à sustentação da organização, especialmente no curto prazo. Já as dimensões ética e filantrópica, apesar de serem muito importantes para que uma organização se constitua socialmente responsável, no curto prazo não impactam tanto na sustentabilidade da empresa, embora tenham grande relevância no sucesso organizacional a longo prazo. 


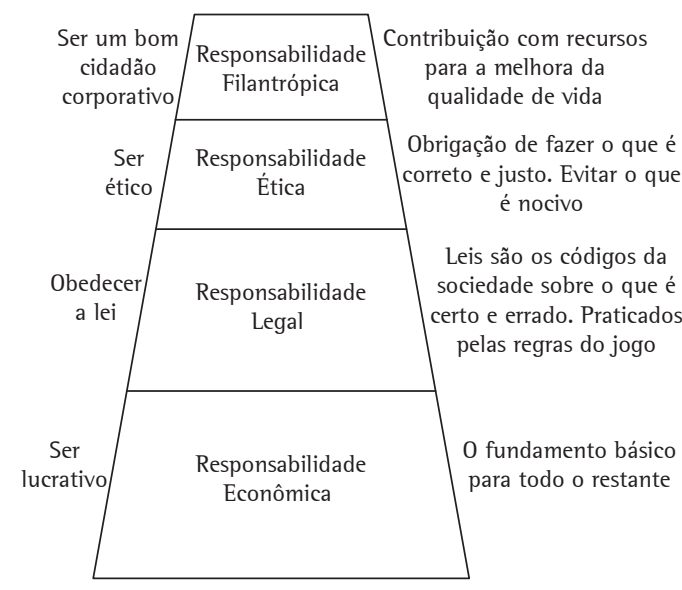

Figura 1. Pirâmide da Responsabilidade Social Corporativa. Fonte: Carroll (1991).

\section{A responsabilidade social e a geração de vantagem competitiva}

Entende-se, neste trabalho, a partir da concepção da maior parte dos autores pesquisados, que a RSC é apenas mais uma estratégia das empresas para alcançar sua finalidade principal e tradicional, o lucro. Este ganho, contudo, não se dá diretamente no âmbito financeiro, na maior parte das vezes, mas principalmente, na constituição de uma reputação positiva que a organização firma com a RSC. Ou seja, as empresas buscam a RSC como forma de reforçar suas marcas, o que a torna uma simples estratégia mercadológica.

Srour (2003, p. 43) sintetiza:

A bem da verdade, em ambiente competitivo as empresas têm uma imagem a resguardar, uma reputação, uma marca. $\mathrm{E}$, em países que desfrutam de estado de direito, a sociedade civil reúne condições para mobilizar-se e retaliar as empresas socialmente irresponsáveis ou inidôneas.

Os autores deste estudo, portanto, defendem que na maioria dos casos os gestores das empresas têm como objetivo final para seu trabalho o constante aumento da lucratividade e por isso agem racionalmente na busca dessa meta, de maneira que não seria diferente em relação à RSC. Pensando-se então na Pirâmide de Carroll (1991), as dimensões legal, ética e filantrópica são preenchidas por serem condições para o cumprimento da dimensão econômica.

Assim como Soares (2004, p. 4) observou:

Tem-se observado, todavia, que por trás do "discurso cobertura [a autora refere-se ao discurso público das empresas sobre suas ações de RSC]", que deixa transparecer apenas as boas intenções e as motivações socialmente admissiveis para esse novo paradigma organizacional (a responsabilidade social), existem outras razões que levam as organizações a aderir ao movimento pelo social, razões essas que nem sempre são assumidas publicamente e, em sua maioria, não são questionadas pelo mundo acadêmico.

Srour (2005) defende ainda que as sociedades contemporâneas, especialmente nos países desenvolvidos, têm passado por um intenso processo de universalização do ensino, de acesso à informação e, consequentemente, de reorganização. Isso tem permitido aumentar o poder de pressão desses grupos sobre as organizações estatais e, sobretudo, empresariais, de tal forma que essas instituições proporcionem à sociedade uma qualidade de vida cada vez melhor. Xavier e Maranhão (2008), de maneira semelhante, entendem que a RSC é um mero mecanismo de geração de vantagem competitiva, atendendo à função central da empresa capitalista, o lucro. Munila (2005) também defende este ponto de vista, ao afirmar que uma política pró-ativa de RSC ajuda a resguardar as organizações de divergências com stakeholders diversos, o que gera vantagem competitiva para as empresas.

Vale também destacar que já existem estudos que contemplam o uso da RSC como um diferencial que impacta positivamente nas vendas de determinados setores (SERPA, 2006). Além disso, ações de responsabilidade social, como o patrocínio de causas sociais ou projetos que visam ao equilíbrio ambiental, geram custos altos para as organizações (LOPEZ, 2007). Ou seja, sob a óptica da maximização dos recursos, essas despesas só são assumidas pelas empresas por gerarem retorno positivo.

Alguns dos principais livros de marketing utilizados nas universidades também já trazem essa concepção (KOTLER, 2000; BAKER, 2005; SHIMP, 2003) quando tratam do marketing social que diz respeito ao uso de estratégias de RSC como diferenciais competitivos. Higuchi et al. (2007) e Garay (2004) observam da mesma forma que a RSC é uma estratégia de marketing que visa, sobretudo, ao reforço da imagem de marca. Muitas vezes são usadas também no contexto da RSC fundações corporativas que associam o nome da empresa a ações de filantropia, agregando às organizações ganho de imagem e reputação (BORGES; MIRANDA; VALADÃO JÚNIOR, 2007).

A RSC neste raciocínio surge na maioria das oportunidades em função de uma pressão externa à organização e não por uma questão de princípio ético ou altruísta dos gestores. 
Nesse contexto, a maneira que as organizações têm para fazer com que a RSC gere retorno é a divulgação maciça das ações dessa natureza dirigidas aos mais diferentes públicos. As empresas, principalmente as de grande porte, têm por isso buscado salientar suas ações socialmente responsáveis em seus diversos anúncios, dirigidos aos mais diversos públicos internos e externos (OLIVEIRA, 2005; TREVISAN, 2002).

Levando-se em consideração esse debate, este artigo pretende demonstrar, a partir do Modelo de Carroll (1991), que o que realmente motiva a RSC é o fortalecimento da imagem organizacional. $\mathrm{Ou}$ seja, objetivou-se a partir dessa análise corroborar o proposto, que as empresas lançam mão de um discurso socialmente responsável, pautado especialmente na ética e na filantropia, como forma de reforço de imagem e marca corporativa. Para tanto, foi escolhida como objeto de análise uma mídia muito utilizada hoje em dia pelas empresas: o Balanço Social Corporativo.

\section{Os balanços sociais corporativos (BSC)}

0 BSC tem como objetivo principal tornar transparentes ativos e passivos socioambientais e econômicos das organizações. Para Oliveira (2005), o Balanço Social visa não apenas informar aos stakeholders o que tem sido realizado pelas empresas mas também a forma com que este Balanço é feito.

A definição do padrão Global Reporting Initiative (2006), também conhecido por GRI - que é um dos principais padrões atuais no mundo para a construção de BSCs e que foi utilizado como referência pelas duas empresas pesquisadas neste estudo -, resume bem a concepção desses materiais:

Elaborar relatórios de sustentabilidade é a prática de medir, divulgar e prestar contas para stakeholders internos e externos do desempenho organizacional visando ao desenvolvimento sustentável. "Relatório de sustentabilidade" é um termo amplo considerado sinônimo de outros relatórios cujo objetivo é descrever os impactos econômicos, ambientais e sociais (tripple bottom line) de uma organização, como o relatório de responsabilidade social empresarial, o balanço social etc. Esse tipo de documento deve oferecer uma descrição equilibrada e sensata do desempenho de sustentabilidade da organização relatora, incluindo informações tanto positivas como negativas. Um relatório de sustentabilidade baseado nas Diretrizes da GRI divulga os resultados obtidos dentro do período relatado, no contexto dos compromissos, da estratégia e da forma de gestão da organização (GRl, 2006, p. 4).

Isso significa que o Balanço Social deve ser uma mídia de prestação de contas clara e objetiva em relação aos impactos econômicos e socioambientais das atividades organizacionais, mesmo que essa prestação possa ser negativa para a imagem ou valor de marca da instituição - é a mesma lógica de um balanço financeiro, onde as informações positivas e negativas têm de ser apresentadas da mesma forma e com o mesmo peso. Na prática, contudo, as empresas brasileiras em geral utilizam seus BSCs como instrumentos para enaltecer seus projetos socioambientais, seu desempenho econômico e seus produtos e serviços, relatando nesses veículos apenas os aspectos positivos das suas ações e ocultando os impactos negativos da sua relação com os seus públicos e com o meio ambiente, ou seja, eles servem mais como instrumento de reforço de imagem (OLIVEIRA, 2005; LEWIS; UNERMAN, 1999; ANDRADE et al., 2002), como qualquer outra propaganda.

Vale destacar que essa mídia foi escolhida como objeto de análise neste estudo em função dos seu objetivo de tornar transparente as informações e prestações de contas. Se nos Balanços Sociais as empresas declaram basicamente aquilo que querem e fazem de positivo, provavelmente nas outras mídias, como internet e folders corporativos, onde não há sequer essa prerrogativa, o discurso para reforçar a imagem de uma empresa socialmente responsável será ainda mais forte.

\section{Metodologia e objetos de análise}

Esta avaliação é de natureza exploratória (GlL, 2006), pois não foram encontrados estudos anteriores com análises como as que foram feitas neste trabalho utilizando o framework de Carroll (1991) como suporte. Além disso, a amostra não tem uma definição sistemática a partir do universo de BSCs no Brasil.

Foram escolhidos para responder aos questionamentos duas empresas siderúrgicas de Minas Gerais. Optou-se por organizações desse ramo em função do alto impacto socioambiental e econômico que causam. Salienta-se que as organizações estão entre as 20 maiores do Estado em termos de faturamento, de acordo com levantamento realizado pelo jornal Estado de Minas (ESTAD0, 2007). As empresas, por não terem sido consultadas para a realização desta pesquisa, não serão identificadas mas denominadas Empresa A e Empresa B. 
Para a análise desses materiais foram utilizadas três metodologias de natureza qualitativa, sendo que duas se enquadram em tipos de análise de conteúdo e a terceira em análise de fotografia e semiótica. Cabe ressaltar que esses métodos permitem reproduzir de maneira bastante fiel o discurso dos autores das publicações (BAUER, 2007) - ou seja, a direção das empresas siderúrgicas. A partir deles é possível, por exemplo, demonstrar a imagem que as empresas siderúrgicas planejam transmitir a seus públicos através dos seus Balanços Sociais.

Salienta-se que a Análise de Conteúdo (AC) visa denotar de maneira plausível elementos ocultos da linguagem humana, além de organizar e possibilitar a descoberta de significados originais dos elementos manifestos (BARDIN, 2004). 0 que se pretendeu com a utilização da $A C$ é identificar variáveis, restrições, motivações, atitudes, crenças e tendências explícitas e implícitas presentes nos balanços sociais. A AC, além disso, possibilita também desvelar aspectos ideológicos que podem existir em dispositivos como diretrizes e princípios, os quais se acredita aqui possam ser encontrados no que é subjacente ao pensamento acerca das estratégias das empresas.

A Análise de Conteúdo, e os vários tipos de métodos de pesquisa que ela abarca, assim como os métodosdeanálise de fotografiaseimagens, são muito usados e corroborados no meio da pesquisa social (BAUER, 2007). Neste artigo, as três metodologias foram utilizadas para aumentar a validade geral da pesquisa, em uma forma de triangulação de ferramentas metodológicas. Pretendeu-se que uma confirmasse a outra, de forma a acrescer o valor deste estudo e para que as avaliações finais fossem as mais próximas possíveis daquilo que as empresas de fato declaram em seu Balanço. Trata-se, aqui, de uma leitura dos autores, amparados por aspectos intersubjetivos, acerca do que foi comunicado pelas empresas. Essa característica é ainda mais relevante na análise de fotografias, nas quais os processos de intersubjetividade se intensificam (LOlZOS, 2007; PENN, 2007).

\subsection{Tipos de análise}

0 primeiro método, chamado de Tipo 1 de Análise, foi a Análise de Conteúdo Temática (BAUER, 2007), que propõe que algumas perguntas referentes ao objeto de pesquisa sejam respondidas com fragmentos do texto. Este método é denominado por Bardin (2004): Análise de Respostas a Questões Abertas. Ou seja, há neste caso um processo de categorização adotado para todos os Balanços Sociais. Neste caso, os temas são utilizados como unidades de registro que permitam estudar motivações, atitudes, valores, crenças e tendências dos autores.
Salienta-se que cada pergunta, referente a cada dimensão do modelo de Carroll (1991), foi respondida com pelo menos dois fragmentos do Balanço Social. Além disso, buscaram-se partes que apoiassem o compromisso das empresas com o cumprimento das dimensões da RSC de Carroll (1991). Neste caso, os critérios para a escolha dos fragmentos foram:

- Dimensão econômica: textos que afirmam o compromisso da organização com o retorno econômico ou com a eficácia produtiva - por exemplo, textos que abordam o lucro para os acionistas e a satisfação dos clientes;

- Dimensão legal:textos que afirmam o compromisso da organização com o cumprimento das diversas legislações vigentes - por exemplo, textos que abordam o cumprimento de legislações ambientais ou contábeis;

- Dimensão ética:textos que afirmam o compromisso da organização com o tratamento justo e equitativo de todos os públicos, ou mesmo da responsabilidade da empresa em relação às questões ambientais - por exemplo, textos que abordam os programas de desenvolvimento dos empregados e de sustentabilidade ambiental - e mesmo em relação aos valores morais da sociedade;

- Dimensão filantrópica: textos que afirmam o compromisso altruísta da organização com comunidades carentes e outros públicos de interesse - por exemplo, textos que relatam ações de voluntariado dos empregados ou doações realizadas pela empresa.

As perguntas foram definidas da seguinte forma:

1) Como a empresa $X$ responde ao cumprimento das várias esferas da dimensão econômica da RSC - de acordo com o modelo de Carroll (1991) - em seu balanço social?

2) Como a empresa $X$ responde ao cumprimento das várias esferas da dimensão legal da RSC - de acordo com o modelo de Carroll (1991) - em seu balanço social?

3) Como a empresa $X$ responde ao cumprimento das várias esferas da dimensão ética da RSC - de acordo com o modelo de Carroll (1991) - em seu balanço social?

4) Como a empresa $X$ responde ao cumprimento das várias esferas da dimensão filantrópica da RSC - de acordo com o modelo de Carroll (1991) - em seu balanço social?

As perguntas foram formuladas pelos autores deste trabalho tendo em vista os objetivos deste artigo. Salienta-se que o mesmo foi feito para os demais tipos de análise, que também foram moldadas para este estudo - baseadas nas orientações de Bauer (2007), Bardin (2004), Loizos (2007) e Penn (2007). 
A segunda parte de análise, denominada Tipo 11 de Análise dos BSCs, refere-se às fotografias. De acordo com Loizos (2000), as imagens fotográficas têm papel decisivo, especialmente em materiais publicitários, na interpretação que fazem os leitores. Em função disso, o autor apresenta três razões para a utilização deste tipo de pesquisa nas ciências sociais: a primeira é o poder de registro que as imagens oferecem; a segunda é que as informações sociais não escritas são importante fonte de dados primários na pesquisa social; e a terceira é que as imagens não escritas têm grande influência no dia-a-dia das sociedades contemporâneas, uma vez que as pessoas são constantemente expostas a fotografias, logo-marcas e símbolos visuais diversos, que influem diretamente em seu cotidiano.

Salienta-se que os BSCs são repletos de artifícios estéticos semelhantes a qualquer material publicitário, como design refinado ou ilustrações diversas - todos eles, por exemplo, utilizam cores leves ou que remetam à natureza -, mas aqui foram avaliadas apenas as fotografias, como uma forma de padronização da análise. Essas fotos foram separadas por categorias que se enquadram no Modelo de Carroll (1991) e foi feita uma avaliação da porcentagem de imagens em relação ao número de páginas do Balanço Social e do total de fotografias de cada dimensão sobre o total de fotos. Desta forma, as imagens foram separadas entre as categorias econômica, legal, ética e filantrópica. A segmentação foi feita de acordo com o texto a que a fotografia se refere ou com o próprio conteúdo da foto - por exemplo, imagens de produtos bem acabados da empresa ou de unidades industriais portentosas se enquadraram na dimensão econômica. Enfatiza-se que as fotos nesse tipo de material são instrumentos de validação do texto e vice-versa (PENN, 2007). Foram usados ainda exemplos de algumas fotos - que foram descritas - e dos textos a que elas se referem, a fim de demonstrar o critério da categorização e a coerência no julgamento.

Fez-se também um pequeno julgamento geral das fotografias dos Balanços Sociais, de forma a avaliar se elas comprometem ou reforçam a imagem da empresa. Apesar da interpretação de uma foto ser extremamente subjetiva (PENN, 2007), Loizos (2000) salienta que na propaganda valores morais da sociedade costumam ser destacados nas fotografias, pois assim a imagem da empresa ou de seus produtos é reforçada positivamente. Essa análise também é importante, pois nesse tipo de foto, conforme destaca Loizos (2000), a imagem é planejada. Ou seja, a fotografia é pensada, é "montada", fazendo com que o seu resultado final reforce aquilo que a empresa deseja transmitir a seus públicos alvos.
0 julgamento desta análise seguiu os seguintes critérios:

- Dimensão econômica: imagens ligadas à produtividade, lucratividade, ganhos operacionais, qualidade de produtos e serviços, relacionamento com clientes, fornecedores e acionistas etc.;

- Dimensão legal: imagens ligadas ao cumprimento das legislações diversas;

- Dimensão ética: imagens ligadas à idéia de relacionamentos justos da empresa com seus diversos stakeholders, imagens ligadas às ações de sustentabilidade ambiental, imagens ligadas a valores morais da sociedade;

- Dimensão filantrópica: imagens ligadas às ações de filantropia da empresa com as comunidades de relacionamento, com a doação, com os trabalhos de voluntariado etc.

Ressalta-se que nos BSCs é comum que exista mais de uma foto por página.

A última unidade de análise, denominada Tipo 111 de Análise, foi a da categorização por páginas. Nesta etapa, as páginas foram segmentadas de acordo com seu assunto principal, tendo como base as dimensões de Carroll (1991). Assim, o tema predominante determinou em que dimensão a página se enquadraria. Neste caso, por exemplo, quando a empresa utilizou a página, ou a maior parte dela, para relatar suas ações de responsabilidade para com os empregados, considerou-se o conteúdo primordialmente ético. As páginas que continham apenas fotografias também foram avaliadas. Há ainda páginas que não puderam ser categorizadas em função do seu conteúdo, como índices, páginas em branco, dentre outras. Em função disso, há menos páginas nas categorias do que o total de páginas dos Balanços.

A escolha desse método deu-se porque em muitos momentos as empresas falam de um assunto dentro do tópico de outro. Em alguns casos, por exemplo, quando relatam os ganhos que os acionistas vêm obtendo, procuram ressaltar com uma foto, que muitas vezes ocupa a maior parte da página, e um texto, destacado por fonte e cores diferenciadas, que a empresa se preocupa com a sustentabilidade e a justiça.

As páginas foram divididas da seguinte forma:

- Dimensão econômica: assuntos e imagens ligados à produtividade, lucratividade, ganhos operacionais, qualidade de produtos e serviços, relacionamento com clientes, fornecedores e acionistas etc.;

- Dimensão legal: assuntos e imagens ligados ao cumprimento das legislações diversas;

- Dimensão ética: assuntos e imagens ligados à idéia de relacionamento justo da empresa com seus 
diversos stakeholders, assuntos e imagens ligados às ações de sustentabilidade ambiental e a valores morais da sociedade;

- Dimensão filantrópica: assuntos e imagens ligadas às ações de filantropia da empresa com as comunidades de relacionamento, como a doação, os trabalhos de voluntariado etc.

Mais uma vez salienta-se que em toda a análise o julgamento dos autores deste trabalho teve papel decisivo, como é comum em uma análise de conteúdo (BAUER, 2007). Nesse contexto, vale observar que a interpretação de uma imagem jamais será idêntica entre duas pessoas. Esse processo é moldado, dentre outros fatores, pela experiência de vida de cada indivíduo, algo absolutamente pessoal e subjetivo (PENN, 2007).

Por esse motivo foram escolhidos três tipos de análise. Acredita-se que assim os vieses apresentados pelo julgamento dos autores, pelos filtros da sua subjetividade analítica, sejam minimizados, aumentando a fidedignidade deste estudo.

Importante ainda observar que as linhas que separam as dimensões de Carroll (1991) são muito tênues, por esse motivo outro leitor poderia fazer interpretações diferentes das deste estudo. As empresas, quando falam das suas ações socioambientais, por exemplo, em geral misturam assuntos relacionados à ajuda que dão às comunidades - o que pode ser considerado um discurso filantrópico - àqueles em que retratam o seu compromisso com o desenvolvimento sustentável e justo com stakeholders - que remetem à dimensão ética.

Também foi feito um relato sobre a impressão geral dos Balanços Sociais em relação ao discurso da RSC - a partir do modelo de Carroll (1991).

\subsection{Análises das empresas}

Há, nos textos referências, endereços e nome de empresas parceiras das organizações pesquisadas que também foram omitidos. Nestes casos, os termos foram substituídos por expressões semelhantes. Por exemplo, quando a empresa cita o nome de um bairro, usou-se a expressão Bairro X. Destaca-se ainda que os fragmentos referem-se a partes diversas dos documentos, como cartas da diretoria, relatórios financeiros e relatórios sociais.

O BSC da Empresa A, que leva o nome Balanço Social e Ambiental 2006, foi publicado em meados de 2007 e refere-se ao ano de 2006. Ele foi feito dentro do padrão GRI. A organização já disponibilizou em seu site o BSC de 2008, mas não em formato PDF e sim como um endereço eletrônico, o que impossibilitou realizar as unidades de Análise 11 e 111. O BSC publicado em 2008, contudo, segue a mesma linha do de 2007, o que diminui o viés ocasionado por essa alteração em relação ao BSC da outra empresa. Já o BSC da Empresa B é chamado Relatório de Sustentabilidade e foi publicado em 2008, referente ao ano 2007. Ele foi feito a partir do modelo GRI.

\subsubsection{Tipo de análise 1}

\subsubsection{Conclusão do tipo de análise 1}

Foi difícil encontrar no BSC da Empresa A fragmentos de textos que abordassem exclusivamente as dimensões econômica e legal da organização (Quadro 1). Além disso, não há textos que comprometam em nada a imagem da empresa. Ao contrário, todos estão associados a informações positivas.

$\mathrm{Na}$ Empresa $\mathrm{B}$ foi mais fácil encontrar fragmentos textuais que falassem exclusivamente do retorno financeiro da empresa (Quadro 1). Há de se destacar também que os textos deste balanço social, mesmo estando longe do ideal, são mais céticos e menos publicitários que os da Empresa A, o que os aproxima mais ao conceito central de um BSC, de acordo com o padrão GRI.

De modo geral, no entanto, o texto da Empresa B ressalta muito os aspectos positivos da organização e deixa de lado os negativos. Além disso, em muitos casos em que a empresa destaca sua busca pelo ganho, ela acrescenta que isso gera retorno para comunidades e demais públicos externos de relacionamento.

\subsubsection{Tipo de análise 11}

No BSC da Empresa A são 55 fotos para 160 páginas e no BSC da Empresa B são 65 fotos para 188 páginas (Tabela 1).

Exemplos de fotos com seus respectivos textos e razões para o enquadramento em uma das dimensões:

Empresa A

- Exemplo 1: Empregados de diferentes níveis hierárquicos da organização, estando alguns uniformizados, enfileirados e sorridentes.

- Texto: "Equipe da Empresa A, compromissada com a Ética."

- Essa foto foi enquadrada na dimensão ética.

- Exemplo 2: Foto de produtos da empresa.

- Texto: “Tubos com rosca: diferencial tecnológico e competitivo da Empresa A."

- Essa foto foi enquadrada na dimensão econômica. 
Quadro 1. Tipo 1 de análise.

\begin{tabular}{|c|c|c|}
\hline Perguntas & Empresa A & Empresa B \\
\hline \multirow[t]{2}{*}{1} & $\begin{array}{l}\text { 1) A busca contínua por uma melhor integração entre } \\
\text { os aspectos econômico, social e ambiental como base } \\
\text { para a sustentabilide da Empresa A, aliada à sinergia } \\
\text { entre os investimentos realizados nos últimos anos } \\
\text { e o cenário favorável do mercado, possibilitou-nos } \\
\text { o alcance de resultados operacionais e financeiros } \\
\text { dos quais podemos nos orgulhar - um lucro líquido } \\
\text { de } R \$ 556 \text { milhões, além de recordes históricos de } \\
\text { produção e faturamento. }\end{array}$ & $\begin{array}{l}\text { 1) } 0 \text { ano de } 2007 \text { foi marcante para a Empresa B. } \\
\text { Conquistamos resultados operacionais e de vendas } \\
\text { excepcionais - com crescimento de } 13,1 \%-\text {, que nos } \\
\text { propiciaram a marca recorde de } R \$ 18,5 \text { bilhões na } \\
\text { geração de receita. }\end{array}$ \\
\hline & $\begin{array}{l}\text { 2) A Empresa A acredita que a satisfação das } \\
\text { expectativas de seus públicos de relacionamento } \\
\text { quanto ao comportamento e desempenho do } \\
\text { Grupo é fundamental para a concretização de seus } \\
\text { planos estratégicos e crescimento saudável dos seus } \\
\text { negócios. }\end{array}$ & $\begin{array}{l}\text { 2) A Empresa B é detentora de uma das dez marcas } \\
\text { mais valiosas do país. lsso é resultado da oferta de } \\
\text { produtos de alta qualidade, do relacionamento de } \\
\text { confiança com clientes e fornecedores, do domínio } \\
\text { tecnológico, da geração de valor para os investidores } \\
\text { e da forte cultura organizacional. }\end{array}$ \\
\hline \multirow[b]{2}{*}{2} & $\begin{array}{l}\text { 1) A Empresa A atende em 100\% a legislação } \\
\text { ambiental, não fazendo uso significativo de gases } \\
\text { poluentes e outras substâncias que intensificam o } \\
\text { efeito estufa e a destruição da camada de ozônio. }\end{array}$ & $\begin{array}{l}\text { 1) } 0 \text { cumprimento dos compromissos da Empresa } \\
\text { B, bem como o monitoramento das boas práticas } \\
\text { de governança, é acompanhado pela Auditoria } \\
\text { Interna Corporativa, subordinada ao Conselho de } \\
\text { Administração. }\end{array}$ \\
\hline & $\begin{array}{l}\text { 2) A empresa conta com as gerências de Segurança } \\
\text { e de Medicina do Trabalho, que têm a missão de } \\
\text { assessorar o Grupo da Empresa A na preservação da } \\
\text { saúde e da integridade dos empregados e no apoio às } \\
\text { unidades gerenciais para o atendimento das metas de } \\
\text { segurança e saúde, melhoria contínua do ambiente } \\
\text { de trabalho e cumprimento da legislação aplicável. }\end{array}$ & $\begin{array}{l}\text { 2) Todos os licenciamentos ambientais e outorgas } \\
\text { de captação e uso de água pela Empresa B estão } \\
\text { disponíveis, de forma detalhada, no site da empresa. }\end{array}$ \\
\hline \multirow[b]{2}{*}{3} & $\begin{array}{l}\text { 1) } 0 \text { Balanço Social e Ambiental da Empresa A procura } \\
\text { espelhar, portanto, o comprometimento do Grupo } \\
\text { com os seus principios de boa governança e com a } \\
\text { evolução social e ambiental não só das comunidades } \\
\text { onde a Empresa está inserida, como também do país } \\
\text { e do planeta. }\end{array}$ & $\begin{array}{l}\text { 1) Essas formas de interação da Empresa B com } \\
\text { os empregados permitem o desenvolvimento de } \\
\text { programas que resultam em benefícios equânimes, não } \\
\text { paternalistas, criteriosamente planejados, observando- } \\
\text { se os anseios dos empregados e seu grupo familiar. }\end{array}$ \\
\hline & $\begin{array}{l}\text { 2) Com seu modelo de gestão baseado na } \\
\text { sustentabilidade, sua atuação efetiva em favor da } \\
\text { cidadania e seu compromisso com a qualidade de } \\
\text { vida e a preservação do meio ambiente, a empresa } \\
\text { atua voluntariamente para o cumprimento das Oito } \\
\text { Metas do Milênio, ajudando na construção de um } \\
\text { mundo melhor. }\end{array}$ & $\begin{array}{l}\text { 2) } 0 \text { relacionamento com os diversos públicos } \\
\text { interessados em suas atividades também é ponto de } \\
\text { destaque nesta publicação, dando continuidade aos } \\
\text { esforços da Empresa B no constante aperfeiçoamento } \\
\text { da comunicação comacionistas, analistas, investidores, } \\
\text { órgãos do governo, empregados, comunidade } \\
\text { impactadas por nossas atividades e entidades sociais } \\
\text { e de proteção e preservação do meio ambiente. }\end{array}$ \\
\hline & $\begin{array}{l}\text { 1) } 0 \text { PROJETO Y é realizado desde } 2004 \text { pela Empresa } \\
\text { A, em parceria com a Empresa X, que é voltada para } \\
\text { a educação socioambiental. Em 2006, o PROJETO Y } \\
\text { envolveu } 50 \text { escolas do entorno da Empresa A, } 20 \text { a } \\
\text { mais que no ano anterior, com a participação de } 40 \\
\text { mil alunos e } 1.450 \text { familiares e educadores. }\end{array}$ & $\begin{array}{l}\text { 1) Os empregados da Empresa B são incentivados a } \\
\text { praticar ações voluntárias em prol do desenvolvimento } \\
\text { social, que incluem trabalho em creches, comunidades } \\
\text { de bairro, igrejas, asilos, hospitais e postos de } \\
\text { atendimento médico e social, além de atuar junto } \\
\text { a ONGs que visam à recuperação de dependentes } \\
\text { químicos e a outras que visam a proteção, a } \\
\text { recuperação e a educação ambiental. }\end{array}$ \\
\hline & $\begin{array}{l}\text { 2) As comunidades do entorno da Empresa A são } \\
\text { consideradas público de relacionamento prioritário } \\
\text { pelo Grupo. Para a Empresa A, a responsabilidade } \\
\text { corporativa para com essas comunidades vai além da } \\
\text { geração de emprego e renda. }\end{array}$ & $\begin{array}{l}\text { 2) A Fundação da Empresa B oferece atendimento } \\
\text { médico e hospitalar a } 21 \text { municípios da microrregião } \\
X \text { de Minas Gerais. Por meio do Hospital Y, centro } \\
\text { de excelência em saúde na região, a população } \\
\text { tem acesso a avançada estrutura física e excelentes } \\
\text { recursos humanos e tecnológicos. }\end{array}$ \\
\hline
\end{tabular}




\section{Empresa B}

- Exemplo 1: Foto de um produto siderúrgico limpo e coberto com um embalagem que leva a marca da Empresa B.

- Texto: "A empresa A é detentora de uma das 10 marcas mais valiosas do país."

- Essa foto foi enquadrada na dimensão econômica.

- Exemplo 2: Foto do teatro que a empresa disponibiliza à comunidade.

- Texto: "Desde 1993, o Instituto da Empresa B atua na promoção da cultura como instrumento de inclusão e desenvolvimento humano e social através do estímulo às diversas manifestações culturais e artísticas, principalmente nas comunidades próximas às suas instalações."

- A foto enquadrou-se na dimensão filantrópica.

\subsubsection{Conclusão do tipo de análise 11}

Percebe-se na Empresa A uma grande prevalência de fotos das dimensões ética e filantrópica, que juntas somam 71\% do total das fotos. Além disso, não há fotos que possam comprometer a imagem da organização, ao contrário, todas sugerem intenção da empresa de reforçar sua imagem. Há, por exemplo, muitas fotos de empregados e pessoas da comunidade sorrindo e uma série de imagens ligadas ao meio ambiente. 0 mesmo aconteceu com a Empresa B, com a diferença de que nesta há um percentual maior de fotos ligadas às dimensões legal e econômica.

\subsubsection{Tipo de análise 111}

\subsubsection{Conclusões do tipo de análise 111}

0 Tipo de Análise 111 (Tabela 1), assim como os demais, reforça que as empresas buscam ressaltar principalmente seus aspectos éticos e filantrópicos, especialmente a Empresa A.

Tabela 1. Fotos e páginas por dimensão de Carrol (1991).

\begin{tabular}{|c|c|c|c|c|c|}
\hline & & \multicolumn{4}{|c|}{ Empresa } \\
\hline & & \multicolumn{2}{|r|}{ A } & \multirow{2}{*}{\multicolumn{2}{|c|}{$\frac{\text { B }}{\text { Frequência }}$}} \\
\hline & Dimensão & & Frequência & & \\
\hline \multirow{5}{*}{ 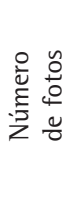 } & Econômica & 16 & 0,29 & 26 & 0,40 \\
\hline & Legal & 0 & 0,00 & 1 & 0,01 \\
\hline & Ética & 30 & 0,55 & 29 & 0,45 \\
\hline & Filantrópica & 9 & 0,16 & 9 & 0,14 \\
\hline & Total & 55 & & 65 & \\
\hline \multirow{5}{*}{ 造芯 } & Econômica & 25 & 0,17 & 72 & 0,42 \\
\hline & Legal & 1 & 0,01 & 7 & 0,04 \\
\hline & Ética & 103 & 0,68 & 71 & 0,41 \\
\hline & Filantrópica & 21 & 0,14 & 21 & 0,13 \\
\hline & Total & 150 & & 65 & \\
\hline
\end{tabular}

\subsubsection{Conclusões das análises 1,11 e 111}

As empresas procuram, na maior parte do conteúdo dos BSCs, transmitir a idéia de que não estão engajadas no lucro e sim na construção de um mundo mais solidário e equitativo.

Interessante observar que nas poucas vezes em que aparecem informações negativas, como tabelas que apresentam o aumento de alguns poluentes na atividade produtiva, não há nenhuma foto para ilustrar esses dados ou textos em que as empresas se comprometam a solucionar os problemas.

Neste caso, seria interessante perguntar por que a Empresa A reduziu seu quadro de empregados em mais de 200 pessoas em um período em que sua lucratividade cresceu em torno de 300\%. Há ética, neste caso, ou preocupação com um "mundo melhor”? Por que não ressaltar essa informação com textos e fotos?

Ou então, por que a Empresa B não mostra fotos dos seus depósitos de carvão mineral, combustível largamente utilizado no local em função do seu baixo custo, mas que é altamente poluente?

\section{Conclusões}

Esta avaliação ajuda a confirmar o já citado, que os Balanços Sociais são utilizados principalmente como instrumentos de reforço de imagem das organizações, sobretudo através da associação das marcas a valores éticos e filantrópicos. A ausência de dados negativos sobre as empresas nessas mídias sugere essa intenção de criar uma imagem socialmente responsável, mesmo que na prática não seja isso que aconteça.

Vale observar que os dois BSCs foram feitos dentro do padrão GRI e que ambos tiveram boas avaliações por empresas de auditoria de renome internacional especializadas em avaliar esse tipo de publicação. Esses resultados, no entanto, podem ter sido influenciados pelo fato de as siderúrgicas contratarem as auditorias como fornecedoras de serviços, ou seja, há uma relação de clientelismo e interesses comuns nestes casos, como o fortalecimento da imagem das organizações que estão publicando. As auditorias, além disso, avaliam apenas a veracidade das informações, e não a ausência delas e a abordagem que lhes é feita.

Nas duas publicações, por exemplo, nas poucas ocasiões em que aparecem dados que possam comprometer a organização - geralmente em tabelas -, não há artifícios estéticos e textuais para corroborar as informações, ao contrário de situações favoráveis às empresas. 
Em relação à teoria norteadora deste estudo, de Carroll (1991), as empresas, mesmo quando falam sobre a dimensão econômica ou legal, não deixam de lado a questão ética e filantrópica. Os fragmentos de textos utilizados como exemplos confirmam isso, como no seguinte trecho no material da Empresa B: "A Empresa B valoriza fornecedores, com foco na ética, transparência e seriedade”.

Além disso, as organizações estudadas citam suas ações como extremamente positivas - mesmo que essas ações não tenham sido tão boas para os públicos a que foram direcionadas -, ressaltando que têm compromisso com o desenvolvimento sustentável e o bem-estar de todos.

Vale lembrar que a prerrogativa do BSC é a prestação de contas, independentemente de serem as ações positivas ou negativas. É importante salientar nesse caso que a capa do BSC da Empresa $\mathrm{B}$ remete à dimensão ética, sendo que nela há a foto de uma folha misturada a imagens de projetos sociais e de árvores. Já no outro, a capa, apesar de não ter fotografias ou textos (por essas razões ela não foi considerada nas análises de Tipo 11 e 111), é verde, sendo que na versão disponível em formato de site há a foto de uma flor na primeira página.

As fotografias do miolo das publicações sugerem que as organizações têm meta bem definida de construir uma reputação socialmente responsável. Percebeu-se, no entanto, que essa estratégia não se pauta na transparência, mas na manipulação das informações que chegam aos públicos diversos. Valeria a pena neste caso questionar por que imagens negativas não são apresentadas, como deveriam ser em uma prestação de contas.

Os resultados sugerem que as empresas percebem que o público não deve pensar que elas existem em função da busca pelo lucro, mas sim como um agente que gera o bem-social. As ações ligadas às dimensões filantrópica e ética, por exemplo, em geral não são mostradas como meios de reforçar positivamente a marca corporativa. As organizações justificam o investimento nessas ações a partir do compromisso que têm com o desenvolvimento sustentável e com o bem-estar de seus públicos de relacionamento. Talvez elas ajam dessa forma na tentativa de influenciar positivamente a percepção de suas atuações pelos respectivos stakeholders. Importante salientar que já existem estudos que compartilham dessa visão, ao mostrar as falhas metodológicas e de propósitos dos BSCs, apontando que essas publicações têm como objetivo geralmente apenas o cumprimento de leis ou o fortalecimento da imagem perante stakeholders e não apresentar informações de forma transparente (OLIVEIRA, 2005; SIQUEIRA; VIDAL, 2002; HINES, 1988; CALIXTO, 2007).
As análises corroboram a premissa deste estudo, de que as organizações pretendem transmitir uma imagem socialmente responsável não a partir da transparência, mas principalmente com a associação de suas marcas a valores éticos e filantrópicos.

Esta avaliação, enfim, indica a necessidade de serem criados mecanismos legais sólidos para que as empresas de fato sejam transparentes naquilo que comunicam em relação às suas ações de RSC e sobre suas intenções. Os resultados sugerem também a importância de que as empresas sejam mais sérias na forma como se declaram em relação à RSC. Neste caso vale destacar que as sociedades têm se mostrado cada vez mais informadas e céticas, e, portanto, é arriscado para as organizações assumirem posturas que não são verdadeiras. Talvez seja o momento de as empresas repensarem suas estratégias de comunicação sobre a RSC, principalmente em relação às suas motivações para essa prática.

\section{Referências}

ASHLEY, P. A. Ética e responsabilidade social nos negócios. São Paulo: Saraiva, 2002.

BAKER, M. Administração de Marketing. Rio de Janeiro: Ed. Campus, 2005.

BARDiN, L. Análise de Conteúdo. 3 ed. Lisboa: Edições 70, 2004.

BAUER, M. W. Análise de conteúdo clássica: uma revisão. ln: BAUER, M. W.; GASKELL, G. Pesquisa Qualitativa com Texto Imagem e Som. Petrópolis, RJ: Ed. Vozes, 2007. p. 189.

BORGES, J. F.; MIRANDA, R.; VALADÃO JÚNIOR, V. M. 0 Discurso das Fundações Corporativas: Caminhos de uma "Nova" Filantropia?. Revista de Administração de Empresas, v. 47, n. 4, p. 101 - 115, 2007.

CARROLL, A. B. Corporate Social Responsibility Evolution of a Definitional Construct. Business \& Society, v. 38, n. 3, p. 268-295, September 1999.

CARROLL, A. B. The Pyramid of Corporate Social Responsibility: Toward the Moral Management of Organizational Stakeholders. Business Horizons, v. 34, n. 4, p. 39-48, July- August 1991.

CHAHAL, H.; SHARMA, R. D. Implications of Corporate Social Responsibility on Marketing Performance: A Conceptual Fremwork. India Journal of Services Research, v. 6, n. 1, p. 371 - 387, 2006.

CALIXTO, L. Responsabilidade Social Corporativa no Brasil: Um Estudo Longitudinal. In: ENCONTRO NACIONAL DA ANPAD - ENANPAD, 31, 2007, Rio de Janeiro. Anais...

ESTADO de Minas. A China é aqui!. Caderno de Economia, 9 de dezembro de 2007.

GARAY, Â. B. S. Voluntariado Empresarial: Modismo ou Elemento Estratégico?. In: ENCONTRO NACIONAL DA ASSOCIAÇÃO DE PÓS GRADUAÇÃO E PESQUISA EM ADMINISTRAÇÃO - ENANPAD, 2001, Campinas, SP. Anais... 
GlL, A. C. Métodos e Técnicas de Pesquisa Social. São Paulo: Atlas, 2006.

HIGUCHI, A. K.; VIElRA, F. G. D. Responsabilidade Social Corporativa e Marketing Social Corporativo:uma proposta de fronteira entre estes dois conceitos. In: ENCONTRO NACIONAL DA ASSOCIAÇÃO DE PÓS GRADUAÇÃO E PESQUISA EM ADMINISTRAÇÃO - ENANPAD, 2007, Rio de Janeiro, RJ. Anais...

HINES, R. D. Financial Accounting: In: Communicating Reality, We Construct Reality. Accounting, Organizations and Society, v. 13, n. 3, p. 251-261, 1988.

KOTLER, P. Administração de Marketing. São Paulo: Ed. Prentice Hall, 2000.

LOIZOS, P. Vídeo, filme e fotografias como documentos de pesquisa. In: BAUER, M. W.; GASKELL, G. Pesquisa Qualitativa com Texto Imagem e Som. Petrópolis, Rio de Janeiro: Vozes, 2007.

MONTORO FILHO, A. F. et al. Manual de Economia - equipe de professores da USP. 3 ed. São Paulo: Saraiva, 2001.

OLIVEIRA, J. A. P. Uma avaliação dos Balanços Sociais das 500 maiores. Revista de Administração de Empresas, v. 4, n. 1, Art. 2, jan./jun., 2005.

PENN, G. Análise semiótica de imagens paradas. In: BAUER, M. W.; GASKELL, G. Pesquisa Qualitativa com Texto Imagem e Som. Petrópolis: Vozes, 2007.

SERPA, D. Efeitos da Responsabilidade Social Corporativa na Percepção do Consumidor Sobre Preço e Valor. Um Estudo Experimental. 2006. Tese (Doutorado em
Administração) - Instituto de Pós-Graduação e Pesquisa em Administração, Universidade Federal do Rio de Janeiro, Rio de Janeiro.

SHIMP, T. A. Propaganda e Promoção: Aspectos complementares da Comunicação Integrada de Marketing. São Paulo: Bookman, 2003.

SIQUEIRA, J. R. M.; VIDAL, M. C. R. Mensuração do impacto social das empresas: Uma abordagem qualitativa aos balanços sociais brasileiros. In: CONGRESSO LATINOAMERICANO DE ESCOLAS DE ADMINISTRAÇÃO (Cladea), 37, outubro 2002, Porto Alegre. Anais...

SINGER, P. A atualidade de Keynes. Jornal Valor Econômico, 14 de novembro de 2002.

SOARES, G. M. P. Responsabilidade Social Corporativa: por uma boa causa!? RAE Eletrônica, v. 3, n. 2, Art. 23, jul./ dez. 2004.

TENÓRIO, F. et al. Responsabilidade Social Empresarial. 2 ed. Rio de Janeiro: Editora FGV, 2006.

TOFFlER, A. A empresa flexível. Rio de Janeiro: Record, 1995.

TREVISAN, F. A. Balanço Social Como Instrumento de Marketing. Revista de Administração de Empresas - RAE Eletrônica, v. 1, n. 2, jul-dez/2002

XAVIER, W. S.; MARANHÃO, C. M. S. A. Responsabilidade Social: a privatização do público. In: ENCONTRO DE ADMINISTRAÇÃO PÚBLICA E GOVERNANÇA DA ANPAD, 3, 2008, Recife - PE. Anais..

\title{
Behind the Social Responsibility Speech of Minas Gerais' Siderurgy
}

\begin{abstract}
The Corporate Social Responsibility (CSR) is a relevant theme and recently it has stimulated lot of scientific debates, focusing on its advantages to business in general and to society. In an effort to explore CSR processes within companies, the main purpose of this study is to analyze the Brazilian Corporate Social Balance. The framework of analysis is based on published contents of the instrument (Corporate Social Balance), for the period of two years. The units analyzed are two large enterprises in the steel sector in Minas Gerais State. We used content and photographic analysis (BAUER, 2007; BARDIN, 2004) to attain the research objectives. To support the content analysis, we used Carroll's Pyramid of Social Responsibility theory (1991) as our theoretical approach. The results show that although companies' discourse focuses mainly on ethical reasons for investing in CSR, the actual motivation is the brand reinforcement and positioning.
\end{abstract}

Keywords

Social responsibility. Social balance. Sustainability. Global Reporting lnitiative - GRl. 